Interactive comment on "The effect of initial water distribution and spatial resolution on the interpretation of ERT monitoring of water infiltration in a landfill cover" by Gaël Dumont et

al.

G. Dumont

gdumont@ulg.ac.be

Received and published: 16 July 2018

\title{
Dear referee,
}

I really thank you for the time you have spent reviewing the manuscript. Indeed, a formatting error occurred when I finalized the manuscript in order to match the HESS format. Section 2.5 has been copied twice, but no text is missing. Numbering for discussion and conclusion is wrong. Correct numbers are: 5-Discussion; 6-Conclusion. 
way to upload a new pdf file for now.

Best regards,

HESSD

Gaël Dumont

Interactive comment on Hydrol. Earth Syst. Sci. Discuss., https://doi.org/10.5194/hess-2018163, 2018.

Interactive

comment 